Original Research

\title{
Effects of Microwave Radiation on Cotton Dyeing with Reactive Blue 21 Dye
}

\author{
Abdul Ghaffar ${ }^{1 *}$, Shahaid Adeel ${ }^{2}$, Noman Habib ${ }^{3}$, Fatima Jalal ${ }^{4}$, Atta-ul-Haq ${ }^{2}$, \\ Bushra Munir', Aftab Ahmad ${ }^{5}$, Muhammad Jahangeer ${ }^{1}$, Qasim Jamil ${ }^{1}$

\begin{abstract}
${ }^{1}$ Department of Biochemistry, Government College University, Faisalabad, 38000, Pakistan.
${ }^{2}$ Department of Chemistry, Government College University, Faisalabad, 38000, Pakistan.

${ }^{3}$ Department of Botany, Government College University, Faisalabad, 38000, Pakistan.

${ }^{4}$ Department of Zoology, Government College University, Faisalabad, 38000, Pakistan.

${ }^{5}$ Department of Biochemistry, University of Agriculture, Faisalabad, 38040, Pakistan.
\end{abstract}

Received: 24 May 2017

Accepted: 24 January 2018

\begin{abstract}
Modern techniques such as microwave treatment as clean and uniform treatment in textile processing have been used to make the dyeing process eco-friendly, plus time and cost effective. The present study is concerned with the effect of microwave irradiation on dyeing of cotton fabric using Reactive Blue 21 dye. Irradiated (RC) and un-irradiated cotton fabrics (NRC) were dyed using irradiated (RS) and un-irradiated (NRS) dye solution under various conditions. Optimal radiation parameters were used to explore dyeing $\mathrm{pH}$, temperature, and time for getting darker shades. ISO standard of color fastness were applied onto cotton fabrics dyed under optimal conditions. We observed that microwave treatment of dye solution for $3 \mathrm{~min}$. showed maximum colour strength onto irradiated fabrics at $60^{\circ} \mathrm{C}$ for $30 \mathrm{~min}$. in the presence of $2 \mathrm{~g} / 100 \mathrm{ml}$ salt as an exhausting agent. The suggested ISO method revealed that MW treatment improved the fastness to light, washing, and rubbing when different shades were made under optimum conditions. We concluded that microwave treatment has not only improved the dyeing behaviour of cotton but also enhanced the colouring characterization using Reactive Blue 21 dye.
\end{abstract}

Keywords: Reactive Blue 21, colourfastness, cotton fabric, spectra flash SF600, crease recovery, microwave radiation

\section{Introduction}

Interest in eco-friendly textile wet processing techniques has increased in recent years due to the increased awareness of environmental issues throughout

*e-mail: aghaffaruaf@yahoo.com the world [1]. Cost-effective ecofriendly textile dyeing by using either safe dyes and chemicals with reduced cost or by employing clean treatment is the choice of the day for the textile industry [2]. Textile dyes are organic compounds that bring bright and firm colour to fabric [3]. Reactive dyes are widely used in the textile industry because of their simple dyeing procedure and good stability during the washing process. It is a class 
of highly colored substances that interacts with fabrics via a covalent bond to impart firm shades [4]. Due to this unique characteristic, reactive dyes have been found to be used increasingly in textile coloration of leather, paper, rubber, plastic, cosmetics, pharmaceuticals, and food [5-6].

Radiation methods, apart from conventional heating, are gaining popularity because these methods are not only naturally safe, clean, and ecofriendly but also cheap in treatment. These help to minimize the energy utilization either by modification in the dyeing process or by tuning the surface of fabrics [7-8]. Microwaves have unique characteristics because they create polarization in dye bath to make it more interactive for fabrics [9]. This uniform and leveled heating source enables dye molecules to diffuse into fabrics more strongly. This energy easily penetrates all the particles of material by instantly and uniformly heating the fabrics, which in turn eliminates the effluents that could occur during conventional heating to make the environment polluted. Limited work is found in the technical literature on pretreatment, dyeing, finishing, surface modification, and surface grafting, sanitizing, and drying/fixing of textile materials, in which microwaves are used as a heat source during dyeing [10-11]. For our current study, Reactive Blue 21 was selected for coloring cotton fabrics under the effect of the microwave treatment.

Reactive Blue 21 dye (Fig. 1) is used for coloring cotton, wool, silk, and polyamide textiles. It is a brilliant

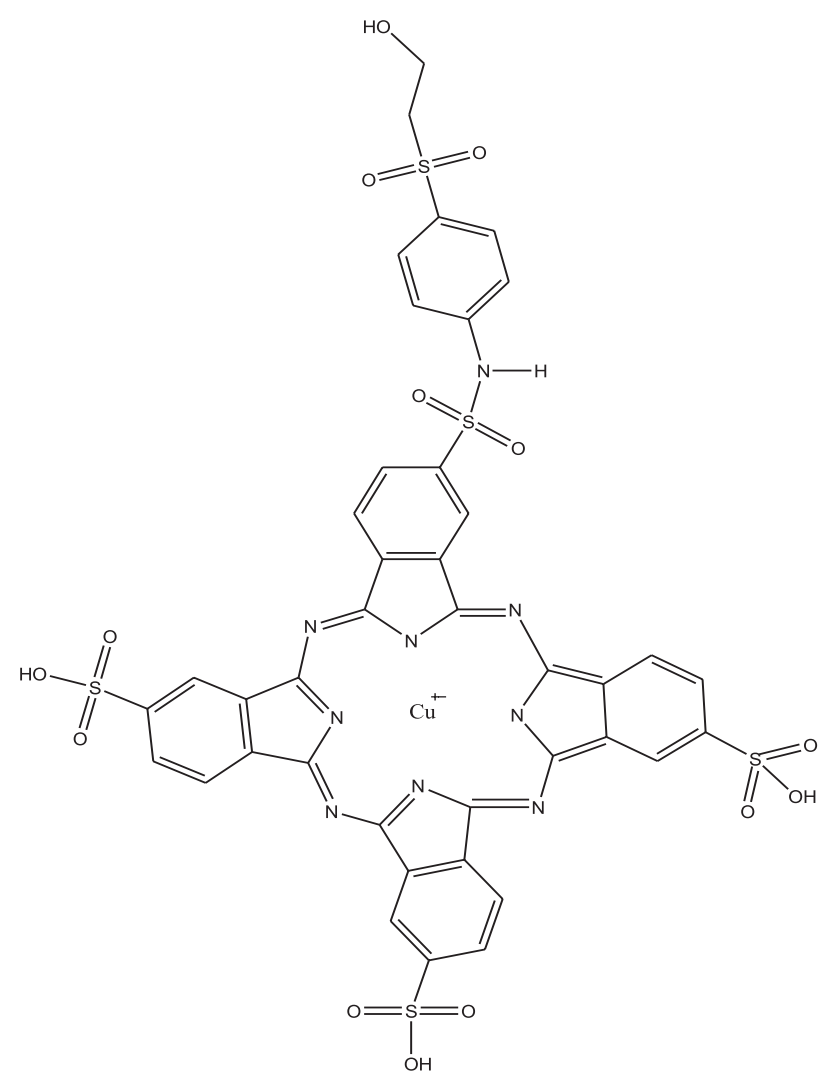

Fig. 1. Reactive Blue 21 dye. bluish turquoise dye having high colour yield with versatile applications with suitability to give pale to dark trichromic shades. It has excellent build-up properties with good all-round fastness properties [12-13].

\section{Material and Methods}

Greige cotton fabrics were purchased from Arshad Market, Jhang Bazar in Faisalabad, Pakistan. They were pre-treated by following the standard methods. Reactive blue 21 dye was purchased from Paragon Dyes and Chemicals in Faisalabad.

\section{Radiation Processes}

The dye solution and pretreated fabrics were exposed to microwave for 1-6 $\mathrm{min}$. using a commercially available microwave irradiator at the Department of Chemistry, Government College University, Faisalabad, Pakistan [14]. After irradiation, the fabrics were dyed at $90^{\circ} \mathrm{C}$ for $60 \mathrm{~min}$. at various $\mathrm{pH}(3,4,7,11$, and 12) in order to attain optimal radiation conditions [15]. After optimizing the irradiation factor, dyeing of optimal fabrics was carried out at $30-75^{\circ} \mathrm{C}$ for $15-60 \mathrm{~min}$. using 1-4 g/L Glauber salt using optimal $\mathrm{pH}$ of dye bath.

\section{Analysis of Fabrics and Solution}

$\mathrm{pH}$ of the dye solution before and after irradiation was carried out in order to detect the significance of any change in the nature of Reactive Blue 21. Similarly, the crease recovery test of fabrics before and after treatment was evaluated using the AATCC method for observing the improvement in pre-treatment of cotton fabrics to make it ready for dyeing [16].

\section{Colour Characteristics Analysis}

All dyed fabrics were investigated in a C1E lab system for $\mathrm{K} / \mathrm{S}$ value through the Kubelka Munk equation computed in Spectraflash SF600, which is equipped with an illumining D $6510^{\circ}$ observer at the Department of Chemistry, Government College University, Faisalabad, Pakistan. The effect of microwave treatment on fastness of dyed fabric was assessed by rating of colourfastness through ISO standard methods of light and washing [17].

\section{Results and Discussion}

The results shown in Table 1 reveal that an increase in radiation time caused a decrease in dye solution $\mathrm{pH}$. Similarly, microwave treatment modifies the crease angle of the fabric. The rise in angle shows that the sorption ability of fabrics has been improved, which influences the dyeing and gives darker shades with high colour characteristics [18]. 
Table 1. Effect of radiation on crease recovery of cotton and $\mathrm{pH}$ of dye solution.

\begin{tabular}{|c|c|c|c|c|c|}
\hline \multicolumn{4}{|c|}{ Radiation effect on crease recovery of cotton fabrics } & \multicolumn{2}{c|}{ Radiation effect on dye solution } \\
\hline $\begin{array}{c}\text { Radiation of cotton } \\
\text { time (Min.) }\end{array}$ & $\begin{array}{c}\text { Initial angle } \\
\theta 1\end{array}$ & $\begin{array}{c}\text { Final angle } \\
\theta_{2}\end{array}$ & $\begin{array}{c}\text { Difference } \\
\theta=\theta_{2}-\theta_{1}\end{array}$ & $\begin{array}{c}\text { Radiation time } \\
\text { (Min.) }\end{array}$ & pH of dye solution \\
\hline Non-radiated & 76 & 82 & 6 & $\mathbf{0}$ & 12 \\
\hline 2 & 72 & 87 & 5 & $\mathbf{1}$ & 11.80 \\
\hline 3 & 70 & 76 & 6 & $\mathbf{2}$ & 11.68 \\
\hline 4 & 68 & 72 & 6 & $\mathbf{3}$ & 11.45 \\
\hline 5 & 65 & 71 & & $\mathbf{5}$ & 11.42 \\
\hline & & & & $\mathbf{6}$ & 11.35 \\
\hline
\end{tabular}

Table 2. Variation of $\mathrm{K} / \mathrm{S}$ value against time of irradiation, dyeing at $3 \mathrm{pH}$, and $90^{\circ} \mathrm{C}$ for 60 minutes

\begin{tabular}{|c|c|c|c|c|}
\hline $\begin{array}{c}\text { Radiation } \\
\text { time (Min.) }\end{array}$ & NRS/NRC & RS/NRC & RS/RC & NRS/RC \\
\hline 1 & 7.3922 & 8.9903 & 6.7116 & 7.7232 \\
\hline 2 & 7.3922 & 7.5323 & 5.4821 & 7.3770 \\
\hline 3 & 7.3922 & $\mathbf{1 1 . 5 7 6}$ & 8.6158 & 7.6610 \\
\hline 4 & 7.3922 & 7.4841 & 7.7666 & 8.6486 \\
\hline 5 & 7.3922 & 5.0857 & 5.0274 & 7.7172 \\
\hline 6 & 7.3922 & 7.6550 & 6.7619 & 8.0592 \\
\hline
\end{tabular}

Table 3. Variation of K/S value against time of irradiation, dyeing at $4 \mathrm{pH}$, and $90^{\circ} \mathrm{C}$ for 60 minutes.

\begin{tabular}{|c|c|c|c|c|}
\hline $\begin{array}{c}\text { Radiation } \\
\text { time (Min.) }\end{array}$ & NRS/NRC & RS/NRC & RS/RC & NRS/RC \\
\hline 1 & 8.9719 & $\mathbf{9 . 6 1 6 3}$ & 8.8429 & 8.7246 \\
\hline 2 & 8.9719 & 7.7401 & 8.2283 & 8.7246 \\
\hline 3 & 8.9719 & 8.9700 & 8.7956 & 8.0451 \\
\hline 4 & 8.9719 & 8.1440 & 7.2146 & 8.3415 \\
\hline 5 & 8.9719 & 7.9405 & 7.2771 & 7.9893 \\
\hline 6 & 8.9719 & 9.1044 & 8.6729 & 8.2250 \\
\hline
\end{tabular}

Table 4. Variation of K/S value against time of irradiation, dyeing at $7 \mathrm{pH}$, and $90^{\circ} \mathrm{C}$ for 60 minutes.

\begin{tabular}{|c|c|c|c|c|}
\hline $\begin{array}{c}\text { Radiation } \\
\text { time (Min.) }\end{array}$ & NRS/NRC & RS/NRC & RS/RC & NRS/RC \\
\hline 1 & 9.5261 & 8.4705 & 8.0795 & 10.129 \\
\hline 2 & 9.5261 & 10.236 & 8.3670 & 10.001 \\
\hline 3 & 9.5261 & $\mathbf{1 3 . 2 2 9}$ & 11.131 & 10.025 \\
\hline 4 & 9.5261 & 8.2964 & 8.9145 & 11.012 \\
\hline 5 & 9.5261 & 10.008 & 8.5366 & 9.6259 \\
\hline 6 & 9.5261 & 8.0019 & 8.9555 & 9.3112 \\
\hline
\end{tabular}

Microwave heating being eco-friendly improved reactive dyeing of cellulosic fabrics using Reactive Blue 21. The results (Tables 2-6) reveal that reactive dyeing under acidic medium ( $\mathrm{pH}$ 3) gives high $\mathrm{k} / \mathrm{s}$ value if the dye bath is radiated for 3 minutes. This is because the microwave treatment helps to reduce particle size of the dye, which improves the diffusion of small molecules into the fabric [19]. Efficient penetration of dye molecules binds firmly with cellulosic fabric and less dye is stripped off in washing, which gives more colour strength observed via spectra flash. The neutral dye bath microwave irradiation for 3 minutes to reactive blue 21 dye (RS) gives high colour strength onto

Table 5. Variation of K/S value against time of irradiation, dyeing at $\mathrm{pH} 11$, and $90^{\circ} \mathrm{C}$ for 60 minutes.

\begin{tabular}{|c|c|c|c|c|}
\hline $\begin{array}{c}\text { Radiation } \\
\text { time (Min.) }\end{array}$ & NRS/NRC & RS/NRC & RS/RC & NRS/RC \\
\hline 1 & 8.7227 & 4.2562 & 3.9464 & 7.5638 \\
\hline 2 & 8.7227 & 4.5284 & 3.8468 & 8.3833 \\
\hline 3 & 8.7227 & 4.7831 & 4.3005 & $\mathbf{8 . 7 1 5 2}$ \\
\hline 4 & 8.7227 & 5.0153 & 4.7805 & 8.1923 \\
\hline 5 & 8.7227 & 4.7116 & 4.8278 & 8.9999 \\
\hline 6 & 8.7227 & 4.2460 & 4.9579 & 6.5705 \\
\hline
\end{tabular}

Table 6. Variation of K/S value against time of irradiation dyeing at $12 \mathrm{pH}$ and $90^{\circ} \mathrm{C}$ for 60 minutes.

\begin{tabular}{|c|c|c|c|c|}
\hline $\begin{array}{c}\text { Radiation } \\
\text { time (Min.) }\end{array}$ & NRS/NRC & RS/NRC & RS/RC & NRS/RC \\
\hline 1 & 8.0540 & 4.8584 & 4.0838 & 5.8580 \\
\hline 2 & 8.0540 & 3.0511 & 2.5073 & 5.4869 \\
\hline 3 & 8.0540 & 3.7193 & 3.4449 & 6.1603 \\
\hline 4 & 8.0540 & 4.4295 & 4.5997 & $\mathbf{6 . 5 2 2 7}$ \\
\hline 5 & 8.0540 & 3.7420 & 3.8893 & 5.8718 \\
\hline 6 & 8.0540 & 2.8385 & 2.7456 & 5.3918 \\
\hline
\end{tabular}


unirradiated fabrics (NRC) (Table 4). This is because irradiation for 1 minute does not raise the kinetic energy of dye molecules and for long-duration radiation the rate of stripping becomes more than a rate of dyeing. Upon washing, unfixed dye is stripped and less $\mathrm{k} / \mathrm{s}$ value is observed. But microwave treatment for $3 \mathrm{~min}$. to dye solution the change in colour depth was found to be promising. Thus, at variable $\mathrm{pH}$ MW treatment for 3 minutes has been optimized of neutral dye bath and is used to dye cellulosic fabric in order to get a darker shade with good colour fastness properties.

Temperature always helps to increase the rate of dyeing and diffusion during reactive dyeing of unirradiated fabrics using an irradiated solution of Reactive Blue 21. Dyeing at low temperature does not accelerate the dye molecules to move topward the fabrics while more heating causes either degradation of colourant or desorption, an effect that - as the coloration

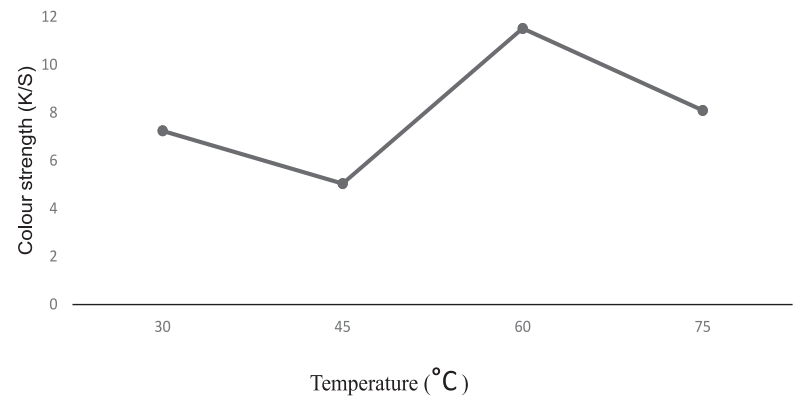

Fig. 2. Effect of dye bath temperature on $\mathrm{k} / \mathrm{s}$ value.

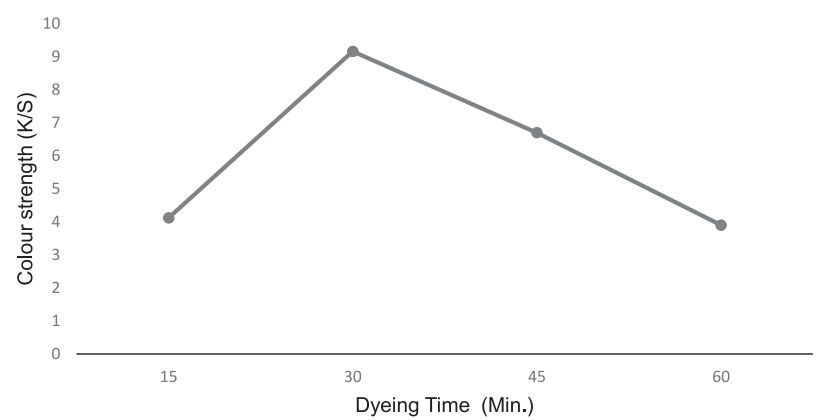

Fig. 3. Effect of time on dyeing un-irradiated cotton fabrics.

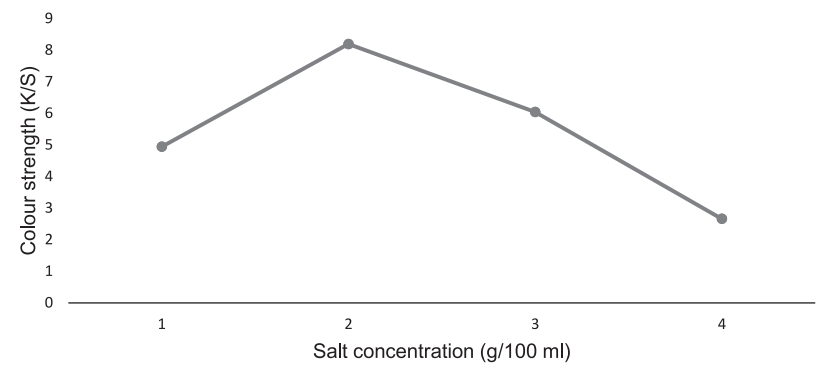

Fig. 4. Effect of salt concentration in dyeing.
Table 7. Washing and light fastness on dyed cotton fabrics with Reactive Blue 21 at different $\mathrm{pH}$.

\begin{tabular}{|c|c|c|c|c|}
\hline \multirow{2}{*}{$\mathrm{pH}$} & \multirow{2}{*}{ Optimum condition } & \multicolumn{2}{|c|}{ Washing effect } & \multirow{2}{*}{ Light effect } \\
\cline { 3 - 4 } 3 & $\begin{array}{c}\text { RS: } 3 \text { min. } \\
\text { NRC }\end{array}$ & $3-4$ & $3-4$ & 4 \\
\hline 4 & $\begin{array}{c}\text { RS: } 1 \text { min. } \\
\text { RC: } 2 \text { min. }\end{array}$ & $3-4$ & $4-5$ & $4 / 5$ \\
\hline 7 & $\begin{array}{c}\text { RS: } 3 \text { min. } \\
\text { NRC }\end{array}$ & $3-4$ & $4-5$ & $4 / 5$ \\
\hline 11 & $\begin{array}{c}\text { NRS } \\
\text { RC: } 5 \text { min. }\end{array}$ & $3-4$ & $4-5$ & $4 / 5$ \\
\hline 12 & $\begin{array}{c}\text { NRS } \\
\text { RC: } 4 \text { min. }\end{array}$ & $3-4$ & 4 & $4 / 5$ \\
\hline
\end{tabular}

process shows in Fig. 2 - reveals that lowering of color strength upon the increase or decrease in color depth $(\mathrm{K} / \mathrm{S})$. Dyeing at optimal tempetratue $\left(60^{\circ} \mathrm{C}\right)$ not only significantly enhances sorption of dye onto fabrics, but also helps achieve good equilibrium of a dye bath, resulting in high colour strength. Reactive dyeing of cotton fabrics is contact time-dependent: the greater the contact time of dye with fabric, the higher the color strength. The results in Fig. 3 show that dyeing for 45 minutes gives maximum colour depth and acceptable fastness characteristics. Hence a reduction in dyeing time proved that microwave heating is a time-effective tool. It showed that $2 \mathrm{~g} / \mathrm{L}$ is the optimal amount of salt to achieve maximum exhausation. Salt adds maximum exhaustion to a dye bath because it tends to neutrilize the dye on fabric. It also creates an atmosphere around the water and dye molecule in such a way that fabric interacts with a dye molecule within a short range of attractive forces, resulting in firm bonding [20]. A low amount of salt does not give promising exhaustion while a high amount causes over-exhaustion, which upon washing affect dyeing strips of colour occurs and low K/S is observed (Fig. 4). Microwave treatment of dye bath for $3 \mathrm{~min}$. reduces the amount of salt used during reactive dyeing of cellulosic fabric (NRC) using an irradiated solution of Reactive Blue 21 (RS), which reveals that MW treatment is a cost-effective tool [21]. The rating results given in Table 7 reveal that microwave treatment of dye solution gives excellent acceptable fastness characteristics because of the presence of the conjugate system and auxochrome in colorant, which offers maximum resistance to detach the colour from fabric. The fabrics dyed under optimal variables are treated with agencies such as heat, crocking, detergents, light, etc., to show maximum resistance to fade, which was confined from rating by grayscale [22]. Thus, the microwave treatment has improved fastness characteristics. 


\section{Conclusion}

The optimum conditions for radiation is non-radiated cotton fabrics and radiated dye solution (NRC/RS) for 3 minutes. Optimum dyeing conditions are $60^{\circ} \mathrm{C}$ for 30 minutes and $2 \mathrm{~g} / 100 \mathrm{ml}$ salt concentration. Low irradiation time for cotton fabric as well as dye solution is more effective to get good colour strength and a bluer shade. It is found that MW radiation not only progresses the colour asset of dye solution but also increases the colour fastness properties on cotton fabrics.

\section{Acknowledgements}

We are thankful to the Higher Education Commission of Pakistan for funding my research work under the HEC-funded project (NRPU/HEC/R \&D/ 2012-2724). We are also thankful to Mr. Zafar Iqbal, manager of the Quality Control Laboratory at Noor Fatima Textile (Pvt), Faisalabad; Mr. Muhammad Abbas, Haris Dyes and Chemicals, Faisalabad; and Mr. Shahid Qadeer of Paragon Dyes and Chemicals Faisalabad for providing us with technical support in this study at lab scale.

\section{Conflict of Interest}

The authors declare no conflict of interest.

\section{References}

1. BHATTI I.A., ADEEL S., SIDDIQUE S., ABBAS M. Effect of UV radiation on the dyeing of cotton fabric with reactive blue 13. Journal of Saudi Chemical Society. 18 (5), 606, 2014.

2. KITKULNUMCHAI Y., AJAVAKOM A., SUKWATTANASINITT M. Treatment of oxidized cellulose fabric with chitosan and its surface activity towards anionic reactive dyes. Cellulose. 15 (4), 599, 2008.

3. KHATRI A., PEERZADA M.H., MOHSIN M., WHITE M. A review on developments in dyeing cotton fabrics with reactive dyes for reducing effluent pollution. Journal of Cleaner Production. 87, 50, 2015.

4. LEWIS D.M., VO L.T. Dyeing cotton with reactive dyes under neutral conditions. Coloration Technology. 123 (5), 306, 2007.

5. LONG J.J., XIAO G.D., XU H.M., WANG L., CUI C.L., LIU J., YANG MU Y., WANG K., CHEN C., REN YI M., LUAN T., DING ZHI-F., LUAN T. Dyeing of cotton fabric with a reactive disperse dye in supercritical carbon dioxide. The Journal of Supercritical Fluids. 69, 13, 2012.

6. HASHEM M., HAUSER P., SMITH B. Wrinkle recovery for cellulosic fabric by means of ionic crosslinking. Textile Research Journal. 73 (9), 762, 2003.

7. CHEN Q., ZHAO T., WANG M., WANG J. Studies of the fibre structure and dyeing properties of Calotropis gigantea, kapok and cotton fibres. Coloration Technology. 129 (6), 448, 2013.
8. SENTHILKUMAR K., SIVA I., RAJINI N., JEYARAJ P. Effect of fibre length and weight percentage on mechanical properties of short sisal/polyester composite. International Journal of Computer Aided Engineering and Technology. 7 (1), 60, 2015.

9. KALE M.J., BHAT N.V. Effect of microwave pretreatment on the dyeing behaviour of polyester fabric. Coloration Technology. 127 (6), 365, 2011.

10. MUGHAL M.J., NAEEM M., ALEEM A., SAEED R., AHMED K. Effect of a cationising agent on the conventional reactive dyeing of cotton. Coloration Technology. 124 (1), 62, 2008.

11. ÖNER E., BÜYÜKAKINCI Y., SÖKMEN N. Microwave -assisted dyeing of poly (butylene terephthalate) fabrics with disperse dyes. Coloration Technology. 129 (2), 125, 2013.

12. SAEED M., HAQ A., MUNEER M., ADEEL S., HAMAYUN M., ISMAIL M., YOUNAS M., SIDDIQUE M. Degradation of direct black 38 dye catalyzed by lab prepared nickel hydroxide in aqueous medium. Global Nest. 18 (2), 309, 2016.

13. RASHID M.A., HOSSAIN M.D., NAKIB-UL-HASAN M., ISLAM M.A. Evaluation of effective jute dyeing process with basic dye and reactive dye. International Journal of Advanced Scientific Engineering and Technological Research. 2 (9), 525, 2013.

14. KHANDAKER S., HASSAN J., OSMAN S. Saving underground water by reusing textile wash water in pretreatment process (scouring and bleaching) of cotton goods. International Journal of Advanced Scientific Engineering and Technological Research. 1 (3), 2012.

15. CHEN K.M., LIN L.H., WANG C.F., HWANG M.C. Interactions between new multi-anionic surfactants and direct dyes and their effects on the dyeing of cotton fabrics. Colloids and Surfaces A: Physicochemical and Engineering Aspects. 356 (1), 46, 2010.

16. HASHEM M., HAUSER P., SMITH B. Wrinkle recovery for cellulosic fabric by means of ionic crosslinking. Textile Research Journal. 73 (9), 762, 2003.

17. NAZ S., BHATTI I.A., ADEEL S. Dyeing properties of cotton fabric using un-irradiated and gamma irradiated extracts of Eucalyptus camaldulensis bark powder. Indian Journal of Fibre and Textile Research. 36, 132, 2011.

18. HASSAN M.S. Crease recovery properties of cotton fabrics modified by urea resins under the effect of gamma irradiation. Radiation Physics and Chemistry. 78 (5), 333, 2009.

19. GORJANC M., BUKOSEK V., GORENŠEK M., VESEL A. The influence of water vapor plasma treatment on specific properties of bleached and mercerized cotton fabric. Textile research journal. 80 (6), 557, 2010.

20. REHAMN F., ADEEL S., SHAKEEL S., SAIF M,J., USMAN M., ZUBAIR M., KAMRAN M., IQBAL M. Radcure improvement in dyeing ability of cellulosic fabric using vat brown - dye. Oxidation Communication 40 (111), 359, 2017.

21. MUNU M., ZUBIR M., AKHTAR N. Polish journal of environmental studies, 2017. (accepted).

22. ADEEL S., SHAHID S., KHAN S.G., REHMAN F.U., MUNEER M., ZUBER M., AKTHAR N. Eco-friendly disperse dyeing of Ultraviolet treated polyester fabric using Disperse Yellow 211 dye. Polish Journal of Environmental Studies. 27 (5), 1935, 2018. 
